Saudi Journal of Medicine

Abbreviated Key Title: Saudi J Med ISSN 2518-3389 (Print) |ISSN 2518-3397 (Online)

\title{
The Retinal Nerve Fiber Layer Thickness in Patients with Alzheimer's Dissease
}

\author{
Fatimah A. Boqoaied $^{1 *}$, Dr. Rania M. Fahmy ${ }^{2}$, Dr. Selwa A. Al-Hazzaa ${ }^{3}$, Dr. Najeeb Qadi ${ }^{4}$ \\ ${ }^{1}$ Senior Optometrist at Dr. Suliman Al Habib Medical Group, Bachelor and Master degree of Optometry and Vision Sciences Saudi Arabia \\ ${ }^{2}$ Ophthalmologist, College of Applied Medical Sciences, King Saud University, Saudi Arabia \\ ${ }^{3}$ Ophthalmologist and Head / Chairman of the Ophthalmology Department, King Fiasal Specialist Hospital and Research Centre Saudi Arabia \\ ${ }^{4}$ Consultant, Department of Neurosciences, King Fiasal Specialist Hospital and Research Centre Saudi Arabia
}

DOI: $\underline{10.36348 / \mathrm{sjm} .2020 . \mathrm{v} 05 \mathrm{i} 02.013}$

| Received: 08.02.2020 | Accepted: 15.02.2020 | Published: 26.02.2020

*Corresponding author: Fatimah A. Boqoaied

\section{Abstract}

Aim: To investigate the retinal nerve fiber layer (RNFL) thickness in patients with Alzheimer disease (AD) without visual impairment using optical coherence tomography (OCT) and to compare the results with healthy control. Study Design: Case Control, Quantities, non-randomized study. Methods and materials: This study was conducted in the neurology and ophthalmology department, King Faisal Specialized hospital, Riyadh, Saudi Arabia from January 2015 to April 2015. Sample: This study was included 22 participants, 11 Alzheimer's patients and 11 healthy controls between the age of 50-75 years old female and male. Examinations: After sinning the informed consent, a number of examinations in the ophthalmology performed and the retinal nerve fiber layer thickness was measured by 3D OCT-2000 Spectral Domain OCT. Statistical Analysis: All statistical analysis was performed using the Statistical Package for the Social Sciences (SPSS), version 21.0, for MacBook Pro. Data were expressed as mean \pm standard deviation. All the data were analyzed and compared using Mann-Whitney U test. A P-value $\leq 0.05$ was considered to indicate statistical significance. Results: Patients with AD showed a significant reduction in the total RNFLT compared to the control group $(84.21 \pm 12.68 \mu \mathrm{m}$ versus $98.27 \pm 16.25 \mu \mathrm{m} ; P=0.006)$. Furthermore, the nasal and inferior RNFL thickness were significantly lower in patients with $\mathrm{AD}$ compared to the controls with a $P=0.007$ and $P=0.010$ in the nasal and the inferior quadrant, respectively. Also, no significant thinning in the temporal and the superior quadrant in AD retinal nerve fiber layer was detected. Conclusion: Patients with Alzheimer disease exhibit a thinner retinal nerve fiber layer (RNFL) than the healthy control subjects.

Keywords: Alzheimer's disease, Retinal nerve fiber layer (RNFL) thickness, Early diagnosis, Visual impairment, Optical coherence tomography (OCT).

Copyright @ 2020: This is an open-access article distributed under the terms of the Creative Commons Attribution license which permits unrestricted use, distribution, and reproduction in any medium for non-commercial use (NonCommercial, or CC-BY-NC) provided the original author and source are credited.

\section{INTRODUCTION}

Alzheimer's disease (AD) became nowadays one of the most common neurological problem worlds widely, that causes a gradual loss of memory with age and is associated with physical and mental problems.

To understand Alzheimer's disease we should know the definition of this disease and its stages, the exact cause, signs, symptoms, diagnosis and finally the treatment of this disease. In this study, we will test the efficiency of a novel eye test in the early diagnosis of Alzheimer's disease, which will help controlling it.

\section{Alzheimer's disease Definition}

Alzheimer's disease is a type of dementia accounts for $60 \%$ to $80 \%$ of all cases of it. ${ }^{1}$ It is a neurodegenerative and physical disease that often attack peoples in old age and cause gradual death of brain cells causing a person to gradually loose cognitive and functional ability and forget time, places, and faces leading to forget himself in the advanced stage [1-3].

Although the speed of advancement of the disease can vary, the average of life expectancy following diagnosis is three to nine years $[4,5]$.

\section{Physiology and Causes of Alzheimer Disease}

Most experts believe that Alzheimer's disease is caused by a buildup of a protein in the brain called amyloid; too much of it affects the way your brain works. The total brain size shrinks with Alzheimer's the tissue has progressively fewer nerve cells and connections gradually $[2,6,7]$. Over time, this damage spreads to several areas of the brain, such as the grey 
matter (responsible for processing thoughts) and the Hippocampus (responsible for memory) (Fig.1).

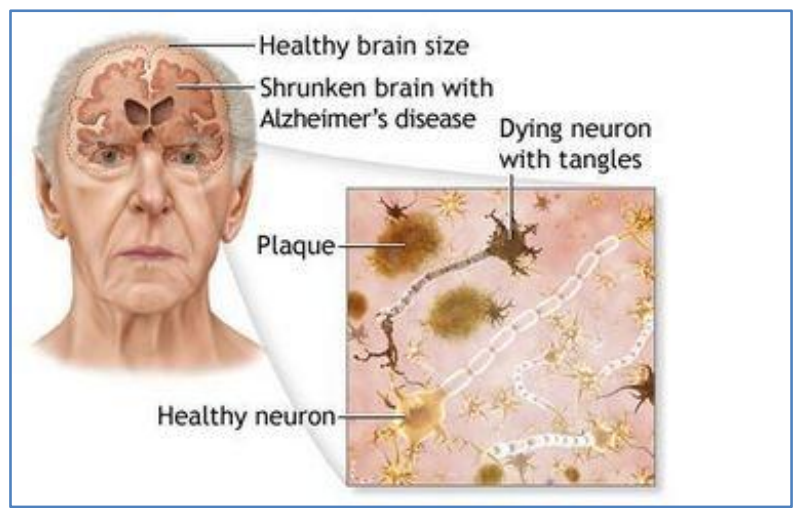

Fig-1: Alzheimer's Brain. (Accessed 20 April 2015)

\section{http://media.mlive.com/chronicle/news_impact/phot o/11820854-large.jpg}

And while amyloid cannot be seen or tested in the living brain affected by Alzheimer's disease, postmortem/autopsy will always show tiny inclusions in the nerve tissue, called plaques and tangles (Fig.2):[6, 7].

- Plaques are found between the dying cells in the brain - from the build-up of a protein called betaamyloid.

- The tangles are within the brain neurons - from a degeneration of another protein called tau protein $[2,6,7]$.

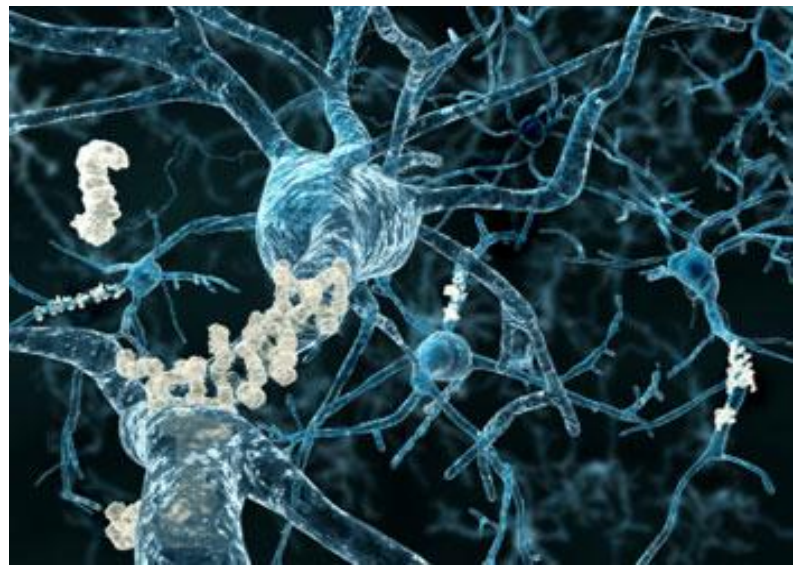

Fig-2: Nerve cells (neurons) in the brain. In Alzheimer's, there are microscopic 'plaques' and 'tangles' between and within brain cells (Accessed 19 April 2015)

http://www.medicalnewstoday.com/images/articles/159442 -alzheimers-brain-neurons.jpg

\section{Stages of Alzheimer}

Most of the references and Scientists classified it as three main stages depending mainly on the symptoms of each stage, as: [2, 3, 8, 9]

- Early Alzheimer's disease

- Mild Alzheimer's disease.

- Advance Alzheimer disease.
On the other hand, it was classified in Alzheimer association by Barry Reisberg as seven stages depending on how abilities change during the course of the disease [10]:

Stage 1: No impairment (normal function)

Stage 2: Very mild cognitive decline (may be normal age-related changes or earliest signs of

\section{Alzheimer's disease \\ Stage 3: Mild cognitive decline}

Stage 4: Moderate cognitive decline (Mild or earlystage Alzheimer's disease)

Stage 5: Moderately severe cognitive decline (Moderate or mid-stage Alzheimer's disease)

Stage 6: Severe cognitive decline (Moderately severe or mid-stage Alzheimer's disease)

Stage 7: Very severe cognitive decline (Severe or latestage Alzheimer's disease)[10].

\section{Symptoms}

Symptoms can be diagnosed at any stage of Alzheimer's disease and it involves mental or behavioral symptoms that interfere with ability to function at work or usual activities.

The rate at which the symptoms progress differs for each individual and it is not possible to predict exactly how quickly it will get worse[3, 8, 9]. Generally, the symptoms of Alzheimer's disease are divided into three main stages (Fig.3):

\section{Early stage symptoms}

In the early stages, the main symptom of Alzheimer's disease is memory loss. For example, someone with early Alzheimer's disease may:

- Forget about recent conversations or events.

- Forget the names of places and objects.

- Repeat them regularly, such as asking the same question several times.

- Poor judgment or find it difficult to make decisions.

- Become unwilling to try out new things or adapt to change.

- Mood swings [8, 9].

\section{Mild stage symptoms}

As Alzheimer's disease develops, memory problems will get worse and someone with the condition may find it increasingly difficult to remember the names of people they know and may struggle to recognize their family and friends.

\section{Other symptoms may also develop, such as}

- Increasing confusion.

- Obsessive and repetitive behavior.

- Illusions (believing things that are untrue).

- Problems with speech or language (aphasia).

- Disturbed sleep.

- Changes in mood. 
- Depression and feeling increasingly nervous.

- Difficulty performing spatial tasks.

- Poor vision or hallucinations.

By this stage, someone with Alzheimer's disease will usually need support to help them with their everyday living. For example, they may need help in eating, washing, getting dressed and using the toilet $[2,3,8,9]$.

\section{Advance stage symptoms}

In the later stages of Alzheimer's disease, the symptoms become severe and troubling for the person with the condition, as well as, their friends, family and cares giving.
A number of other symptoms may also develop as Alzheimer's disease advances, such as:

- Eating and swallowing problems (Dysphagia).

- Difficulty in moving everywhere without assistance.

- Weight loss.

- Urinary incontinence.

- Loss of speech gradually.

- Short- and long-term memory deterioration.

During the advance stage, the patient starts to lose personal hygiene. This stage is the most critical stage that needs intense care and supervision $[8,9]$.

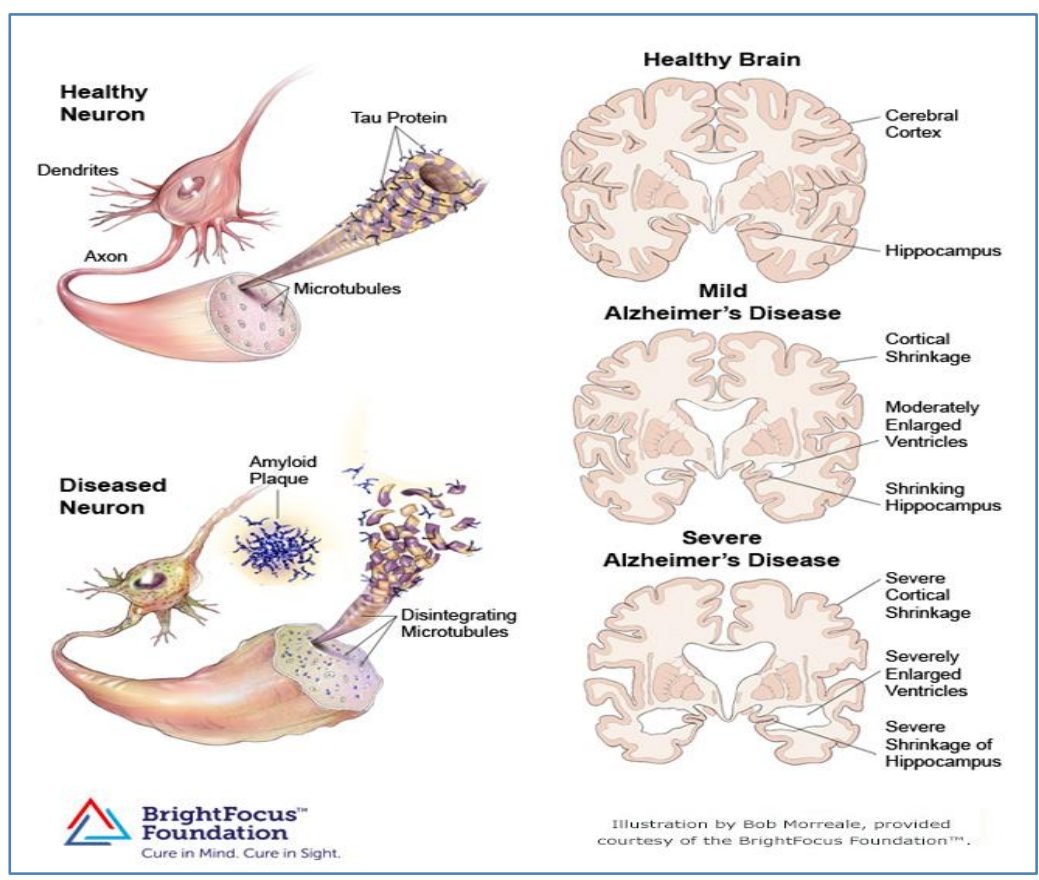

Fig-3: The stages of Alzheimer's disease. Online at: http://www.brightfocus.org/alzheimers/about/understanding/brainnerve-cells.html (Accessed in 20 April 2015)

\section{Risk Factors}

Risk factors associated with Alzheimer's disease include:

\section{Unavoidable risk factors}

- Age $-60-85$, it may start at early age 40 or $50 .^{3,11,12}$

- Family history

- About $70 \%$ of the risk is believed to be genetic. ${ }^{11,12}$

- Female.

\section{Potentially avoidable or modifiable factors}

- Diabetes.

- High cholesterol.

- Depression.

- Hypertension.

- Low educational and occupational skills.

- Head injury.

- Sleep disorders $[2,3,11,12]$.

\section{Diagnosis}

Diagnosing Alzheimer's requires careful medical evaluation; due to the fact that there is no single test that can display whether a person has Alzheimer's disease or no. Therefore, the first thing doctors do is to perform tests to rule out other conditions before confirming whether psychological symptoms and signs are severe enough to be Alzheimer's disease. These tests include [11-13]:

- Patient medical history

- Mental status testing.

- A physical and neurological exam (e.g. by testing balance, senses and reflexes).

- Blood and urine samples.

- Brain scans (Magnetic resonance imaging (MRI) scan, Computerized tomography (CT) scan and Positron Emission Tomography (PET)) (Fig.4) [1113]. 


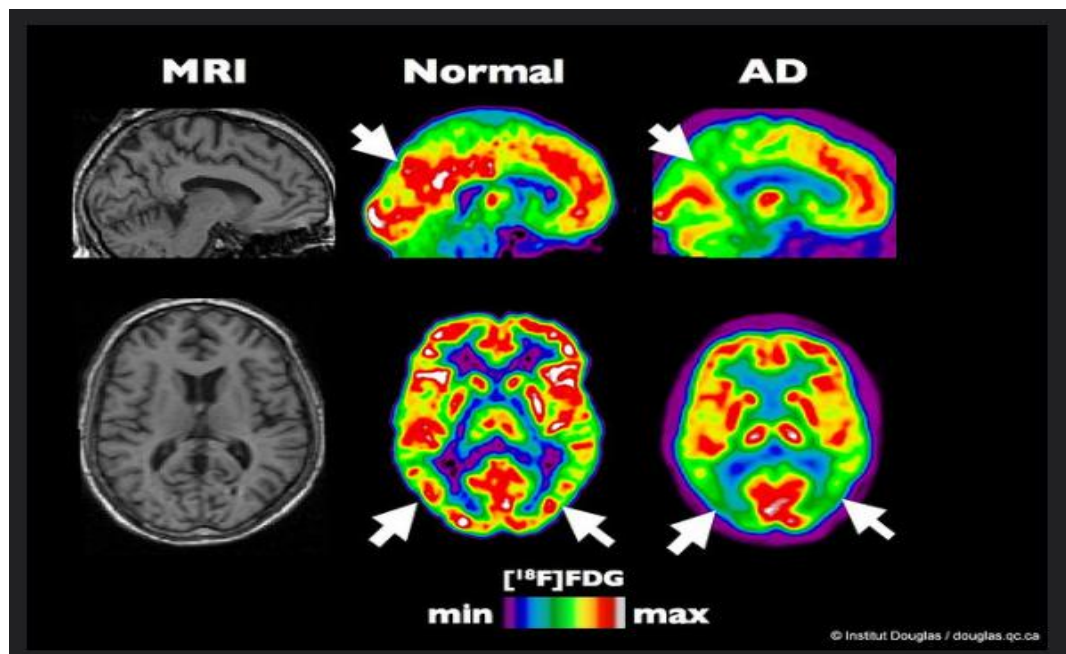

Fig-4: The figure shows MRI, and PET images from a healthy volunteer and an Alzheimer Disease patient. (Accessed in 20 April 2015). Online at: https://www.flickr.com/photos/institut-douglas/2677257668/

In addition to these tests it is very important to check the memory loss and mental performance through cognitive testing.

Hodkinson in 1972 established the general practitioner assessment of cognition (GPCOG) test, which is a website-based assessment designed with 10 effective questions, to be an early reliable indicator for use in the initial consultations of older people in confused states [14].

The mini mental state examination (MMSE): Is a brief quantitative structured test in the form of questionnaire for assessment of the mental status; it takes about 10 minutes to be completed. The MMSE tests global cognitive function, with items assessing: orientation, registration, recall, attention, calculation and language abilities (Fig.5) [10-13].

MMSE scores range from 0 to 30, with scores of 25 or more considered normal. Scores less than 10 indicate severe impairment. People with Alzheimer's disease tend to score in 4 levels:

- Normal cognitive health - score above 26/30.

- Mild-to-moderate Alzheimer's - below 26/30.

- Moderate - below 20 but above 10 .

- Severe - score under $10[10,11,13]$

\section{The Mini-Mental State Exam}

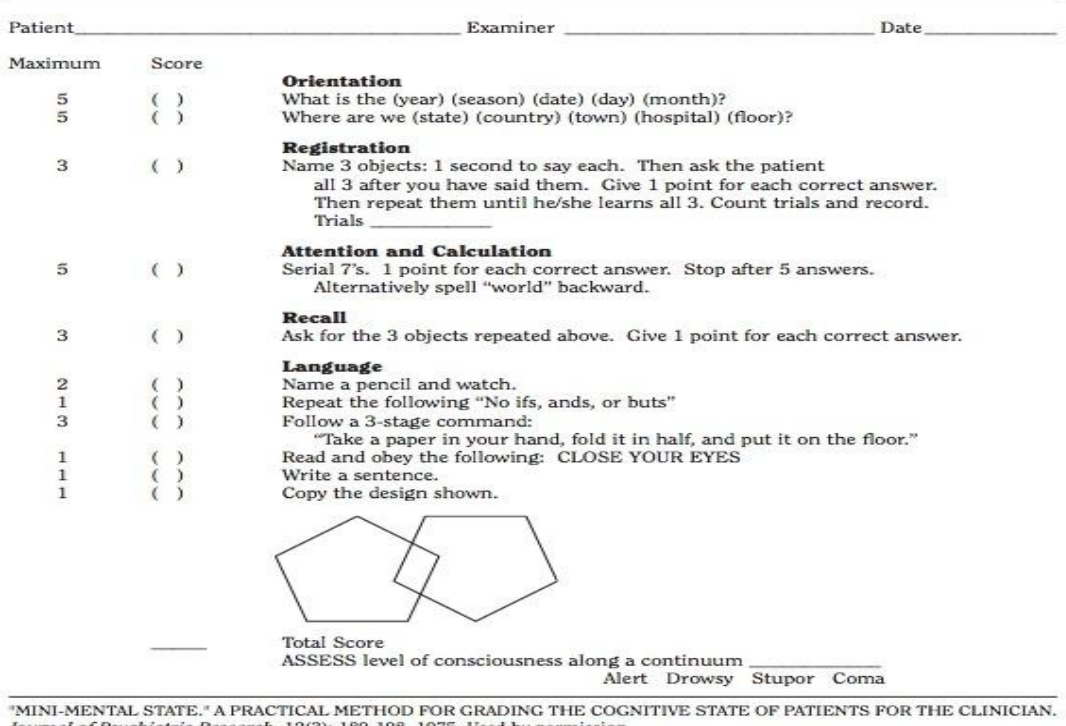

MINI-MENTAL STATE." A PRACTICAL METHOD FOR GRADING THE COGNITIVE STATE OF PATIENTS FOR THE CLINICIAN.

Fig-5: The mini mental state examination (MMSE) screening form. (Accessed in 24 April 2015). Online at: http://ztechzone.net/slinstitute/science/psychology-of-human-behavio-2/the-mini-mental-state-exam.html 


\section{Recent Development in diagnosis of Alzheimer's} disease

- An accurate blood test for Alzheimer's is a future possibility [15]

This blood test highlights and tests a 'signature' panel of 12 mRNAs that are proved to have different levels of dementia [15]

- Peanut butter may help to diagnose Alzheimer's disease[16]

The ability to smell peanut butter is often one of the first things to be affected in cognitive decline generally and in the early stages of Alzheimer's disease specially.

- Measurement of the retinal nerve fiber layer thickness (RNFLT) using the Optical coherence tomography $(O C T)[17]$. OCT shows thinning of RNFL in patients with $A D$, which can help in the early diagnosis of Alzheimer [17].

\section{Importance of the Early Diagnosis of Alzheimer's disease}

Although the onset of Alzheimer's disease cannot yet be stopped or reversed, an early diagnosis help people with dementia and their families to have:

- A good chance to benefit from treatment.

- More time to plan for the future.

- An opportunity to participate in decisions about care, transportation, living options, financial and legal matters.

- Benefit from care and support services, making it easier for them and their family to manage the disease $[10,11,13]$.

\section{Treatment}

No treatments stop or reverse the progression of Alzheimer's disease but some options may reduce its symptoms and help to improve quality of life. There are four drugs in a class called cholinesterase inhibitor approved for symptomatic relief in US: Donepezil (brand name Aricept), Alantamine (Reminyl), Rivastigmine (Exelon) and Tacrine (Cognex) [2, 3, 6].

\section{Retina}

\section{Anatomy and Physiology}

The eye is made up of various components; one of the main structures is the retina. The retina is that's sensitive layer which lining the eye from inside and it is mainly responsible for receiving light stimulus and transfer it to the brain in a form of electrical signs (Fig.6). The retina developed from the optic vesicle, which is an outgrowth of the diencephalon. It remains connected to the diencephalon via the optic nerve [18].

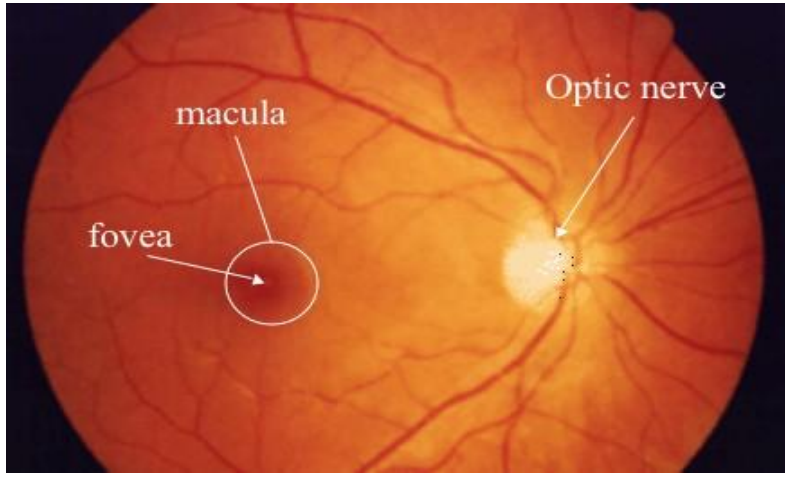

Fig-6: fundus photograph shows the normal appearance of the retina. (Accessed 20 April 2015). Online at: http://www.ssc.education.ed.ac.uk/courses/Pictures/cgil12. jpg

\section{The retina contains mainly two distinct parts}

- Macula: which is located in the center of the retina and centralized by fovea, it is responsible for the distinct vision.

- Optic Disc: located nasal to the fovea of both eyes, The optic nerve is a continuation of the retinal nerve fibers, Visual information is transmitted along the optic nerve to the brain (Fig.6)[18].

The Retina contains $\mathbf{1 0}$ main layers; arranged from inwards as followed (Fig.7):

- Inner limiting membrane

- Optic nerve fibers and axons of ganglion cells.

- Ganglion cell bodies.

- Inner plexiform layer - synapse of bipolar cells with ganglion cells.

- Inner nuclear layer - nuclei of bipolar cells.

- Outer plexiform layer - synapses of photoreceptors with bipolar cells

- Outer nuclear layer - photoreceptor cell nuclei.

- Outer limiting membrane.

- Photoreceptor layer - rods and cones.

- Pigment cells - retinal pigmented epithelium.

It can be seen clearly and examined by the optical coherence tomography (OCT) (Fig.8), which can help in diagnosis of many retinal problems and diseases $[18,19]$.

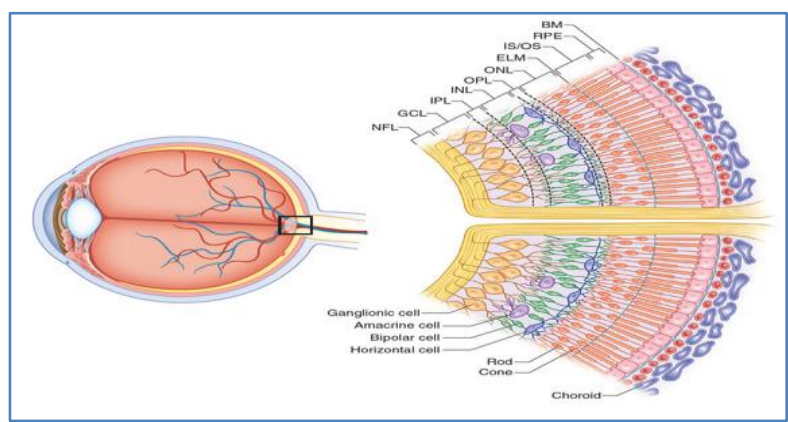

Fig-7: Retinal Layers. (Accessed in 20 April 2015). Online At: http://www.retinareference.com/anatomy/ 


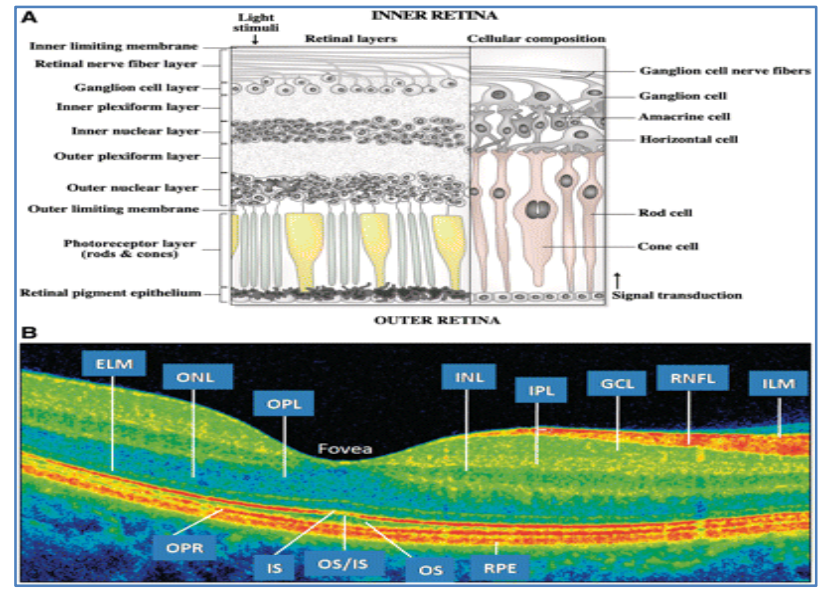

Fig-8: Retinal layers showed by optical coherence tomography. (Accessed in 20 April 2015). Online At: http://brain.oxfordjournals.org/content/brain/early/2011/1 0/17/brain.awr264/F1.large.jpg?width $=800$ \& height $=600 \&$ carousel $=1$

\section{Retinal nerve Fiber Layer}

Ganglion cell axons, or nerve fibers, project anteriorly, and then turn at right angles, running along the surface of the retina. Along with the branches of the central retinal artery and vein, they make up the retinal nerve fiber layer (RNFL). Each axon proceeds in a more-or-less direct course toward the optic disc, located medially to the macula lutea. Axons, which must pass near the macula lutea, arch around it, keeping it free of obstruction (Fig.9) [18-20].

The optic disc is the exit point for the ganglion cell axons. At the optic disc, these axons collect to form the optic nerve and as a group turn at right angles again, plunging through the retina, choroid, and sclera. Because of the high concentration of axons in this area, there are no photoreceptors. For this reason, the optic disc is known as the blind spot $[19,20]$. The retinal nerve fiber layer, which emanates from the optic disc and decreases in thickness toward the macula, can be clearly visualized by OCT (Fig.10) [19].

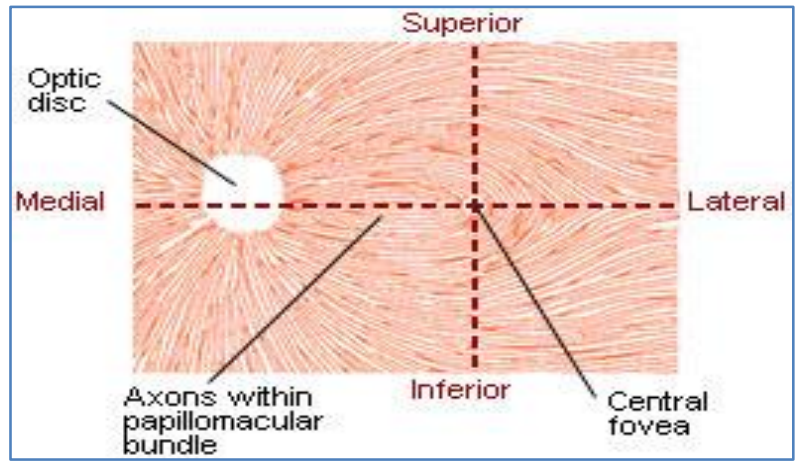

Fig-9: Normal retinal nerve fibers pattern. (Accessed in 20 April 2015). Online at:

http://teaching.pharmacy.umn.edu/courses/eyeAP/Eye_An atomy/media/normal_nerve_pattern.jpg

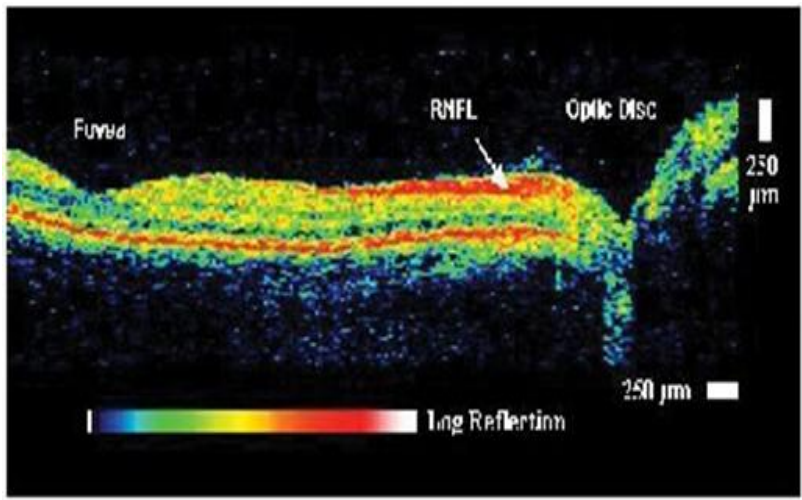

Fig-10: Retinal nerve fiber layer showed by OCT.

(Accessed in 20 April 2015). Online at:

http://www.reviewofophthalmology.com/CMSImagesCont ent/2005/5/1_719_1.jpg

\section{Ocular manifestations in Alzheimer's disease}

Anatomical changes have been detected within the eye before signs of cognitive impairment and memory loss are apparent in AD. Unlike the brain, the eye is a unique organ that can be visualized noninvasively at the cellular level because of its transparent nature, which allows for inexpensive testing of biomarkers in a clinical setting [21-23].

Previous studies have attributed the visual related symptoms to the degeneration in the brain. However, now there is increasing evidence that the visual pathways are involved in $\mathrm{AD}$, it can be represented mainly by optic nerve degeneration and loss of retinal ganglion cells, and it has been suggested that these defects might contribute to visual related problems [22].

Deposits of the Amyloid protein have been found in the eye and acetylcholine is known to be imperative to the retinal cells, so the defect that damages the brain cells reflected on the eye cells [2224].

In the retina, Alzheimer's disease related changes includes mainly: loss of neurons, loss of retinal nerve fibers, increase in optic disc cupping, retinal and functional visual impairment $[24,25]$. Hence, there are also other symptoms related to: visual acuity, perceiving structure from motion, color vision, visual field and spatial contrast sensitivity [21, 26, 27].

\section{Visual acuity (VA)}

In several studies they found that $\mathrm{AD}$ affects the distinct of vision and are compatible with the hypothesis that visual dysfunction in $\mathrm{AD}$ affect the performance of this disease. This could aid in diagnosis and interventions to improve functional capacity in patients with $\mathrm{AD}[26,27]$. 
Visual acuity (VA) is hard to be tested precisely in patients with $\mathrm{AD}$ among the later phases of the disease, yet studies approved that VA can be hard to be assessed also among the early stages of $\mathrm{AD}[21,26$, 27]. This problem caused mainly by the short-memory loss and the quick loss of fixation after the test has been explained to the patient.

\section{Contrast sensitivity}

Deficits in contrast sensitivity (CS) have been reported in Alzheimer's disease (AD)[28]. Yet, the extent of these deficits in the early AD stages, including mild cognitive impairment (MCI) or even earlier, has not well been investigated. However, in one of the studies they report that $\mathrm{CS}$ deficits were found in $\mathrm{AD}$ and MCI, indicating that the measurement of CS is sensitive to early AD-associated changes $[29,30]$.

\section{Color vision}

Color vision test make a significant difference in short-term memory recall ability compared to other tests [31]. Hence, the color vision test will be abnormal in Alzheimer's patient due to the defect of the shortmemory in this disease. This abnormality may give an indication in early stages, helping in controlling the patient status [21, 32].

\section{Visual field}

Few studies were performed on the visual field of Alzheimer's disease (AD). In one study it was reported that the visual deficits is one of the first symptoms of $\mathrm{AD}$, which will aid in its early detection, and accurate diagnosis [21,33].

\section{Eye movement}

The capacity to focus to a target is influenced in AD. Although, it has been known that the saccadic latency [34] and the smooth pursuit movement [35, 36] decrease with age, else, the defect will be more in patients with $\mathrm{AD}$.

\section{Visual hallucination}

Visual hallucination or visual illusions; it means seeing things that does not exist. Increased occipital atrophy in $\mathrm{AD}$ is associated with visual hallucinations.

Many studies support the association of visual hallucinations with the pathology of the visual system across this disorder [21]. Furthermore, it was reported that even if the patient may have a history of visual disorder, his visual hallucinations will be also related to three variables: age, visual acuity in the "best eye," and visual agnosia, which is correctly classified $\mathrm{AD}$ patients as $91 \%$ of hallucinators vs. non-hallucinators[37].

\section{Retinal nerve fiber layer thickness (RNFLT)}

The retinal nerve fiber layer is an extension of the brain neurons. Hence, the continuous loss of the neurons in $\mathrm{AD}$ brain from the earliest stage will be followed by continuous loss of the nerve fibers layer in the retina. This relationship will be detected using a novel test by the optical coherence tomography (OCT) (Fig.10) [17, 38, 39, 40, 41, 42, 43].

Many previous studies published the observation of reduction in RNFLT in the peripapillary retina using several types of OCT [44-47]. In this study we aim to investigate RNFLT in more details among AD patients using TOPCON (3D OCT-2000).

\section{OBJECTIVES \\ Aim of Study}

The aim of this study is to investigate retinal nerve fiber layer thickness (RNFLT) in patients with Alzheimer disease (AD) without visual impairment using optical coherence tomography (OCT) and to compare the results with healthy control. This can help in the early diagnosis of Alzheimer's disease.

\section{Hypothesis}

Patients with Alzheimer disease will exhibit a thinner retinal nerve fiber layer (RNFL) than the healthy control subjects.

\section{MATERIALS AND METHODS Study Design}

Case Control, Quantitive, and non-randomized study.

\section{Subjects}

This study was conducted in the neurology and ophthalmology department, King Faisal Specialized hospital (KFSH), Riyadh, Saudi Arabia from January 2015 to May 2015. A total of 22 subjects, including 19 eyes of 11 subjects with Alzheimer's disease and 22 eyes of 11 healthy controls, the age were ranged from (50-75) years old. 3 eyes of Alzheimer's patients were excluded because:

- Two of the patients were losing their fixation constantly during the examination using the optical coherence tomography.

- One patient has a mature cataract in the left eye.

Both eyes of patients with $\mathrm{AD}$ and controls were examined and imaged using OCT.

\section{Control Subjects \\ Inclusion criteria}

- Refractive error range between \pm 6.00 .

- Normal vision; 20/30 or better.

- Normal Intraocular pressure (IOP).

- Normal anterior segment examination.

- Normal fundus examination.

\section{Exclusion criteria}

- Refractive error over than \pm 6.00 .

- Glaucoma. 
- Age-related macular degeneration and diabetic retinopathy.

- Optic disc anomaly and optic neuropathy.

- Corticosteroids treatment.

- History of ocular trauma.

\section{Alzheimer's patients \\ Inclusion criteria \\ Mental criteria}

Patients with early and mild AD will be enrolled in the study, they well be included if they met the criteria of minimal cognitive disturbance with MMSE at least 20/30 scores.

\section{Ophthalmological criteria include}

- Refractive error range between \pm 6.00 .

- Normal vision; 20/30 or better.

- Normal Intraocular pressure (IOP).

- Normal anterior segment examination.

- Normal fundus examination.

\section{Exclusion criteria \\ Mental criteria}

Subject with moderate and advanced Alzheimer (MMSE below 20/30 scores) will be excluded (with mental impairment).

\section{Ophthalmological criteria}

- Refractive error over than \pm 6.00 .

- Glaucoma.

- Age-related macular degeneration and diabetic retinopathy.

- Optic disc anomaly and optic neuropathy.

- Corticosteroids treatment.

- History of ocular trauma.

\section{Examinations}

After full neurological examination of Alzheimer patients in the neurology clinic in KFSH, patients that met the criteria were convinced to be enrolled in the research and to visit the ophthalmology department on the same day. Control subjects were enrolled from the ophthalmology department if they met the criteria. All the subjects were asked to sign the informed consent.

After talking personal, medical and family history all subjects underwent full ophthalmological examinations in the ophthalmology department for maximum one hour, included:

- Autorefractometer (TONOREF II NIDEK).

- Measurement of the best-corrected visual acuity (BCVA).

- Intraocular pressure (IOP) measurement using (TONOREF II NIDEK).

- Examination of the anterior segment.

- Dilation using Tropicamide (1\%).

- Fundus examination.

- The retinal nerve fiber layer thickness (RNFLT) was measured by the optical coherence tomography using TOPCON (3D OCT-2000) (Fig.11).

\section{Instrument}

Retinal nerve fiber layer thickness was measured using 3D OCT-2000 Spectral Domain (Fig.11). (Temporal, nasal, inferior, superior quadrant and total thickness) peripapillary RNFLT were obtained from the OCT and the same procedures were done for all the participants.

\section{Optical coherence tomography (OCT) Definition}

The optical coherence topography (OCT) is a high resolution, cross-sectional imaging technique that allows detailed assessment of retinal thickness and morphologic evaluation of the retinal layers. With OCT, the exact localization of pathologic feature can be visualized in segmentation maps of the retina. Therefore, it has become an important clinical and research tool for the diagnosis, follow up, treatment and assessment of new treatment modalities for all diseases that affect the fundus $[48,49]$.

\section{Principle}

Optical coherence tomography is based on the principle of Michelson interferometry. Low-coherence infrared $(830 \mathrm{~nm})$ light coupled to a fiber optic travels to a 50/50 beam splitter and is directed through the ocular media to the retina and to a reference mirror, respectively. Light passing through the eye is continuously varied in the reflectivity depends on the different retinal layers. The distance between the beam splitter and the reference mirror is continuously varied. When the distance between the light source and retinal tissue is equal to the distance between the light source and the reference mirror, the reflected light from the retinal tissue and reference mirror interacts to produce an interference pattern. The interference pattern is detected and then processed into a signal. The signal is analogous to that obtained by A-scan ultrasonography using light as a source rather than sound. A twodimensional image is built as the light source is moved across the retina. The image is a series of stacked and aligned a scans to produce a two-dimensional crosssectional retinal image that resembles that of a histological section. The imagining method thus can be considered a form of in vivo histology. An infrared sensitive charge coupled device video camera documents the position of the scanning beam of the retina. The OCT image can display on a gray or a color scale. Highly reflective structures are shown with bright colors (red and yellow), while those with low reflectivity are represented by darker color (blue and dark). Those with intermediate reflectivity appear green. The OCT provides high-resolution measurements and cross-sectional imagining of the retina, optic disc, and the RNFL. RNFLT are calculated from landmarks in the scan. The useful measurement of the RNFLT is made along the optic disc scan [47-50]. 


\section{Clinical applications}

- To evaluate optic nerve head tomography.

- To detect, study and follow any retinal problems.

- The OCT has been used for the diagnosis of many retinal and optic nerve diseases [51,52].

- Some types of OCT can be used for anterior segment imagining.

- $\quad$ To evaluate the RNFL [47-50, 38, 39].

\section{D OCT-2000 Spectral Domain OCT}

The Topcon 3D OCT-2000 System is the first Spectral Domain OCT system to incorporate a high resolution fundus camera and a user friendly color touch screen display in a compact, space saving design (Fig.11, Fig.12). The easy-to-use software enables dynamic viewing of the OCT data, providing 3D, 2D fundus images simultaneously. The 3D OCT-2000 with Topcon's Data Management System provides true connectivity and access to images anywhere, anytime [49].

RNFL thickness measurements generated by 3D OCT-2000 Spectral Domain are interpreted as normal (or abnormal) with the aid of normative databases of RNFL thickness values for age-matched normal, each machine having its own database [49].

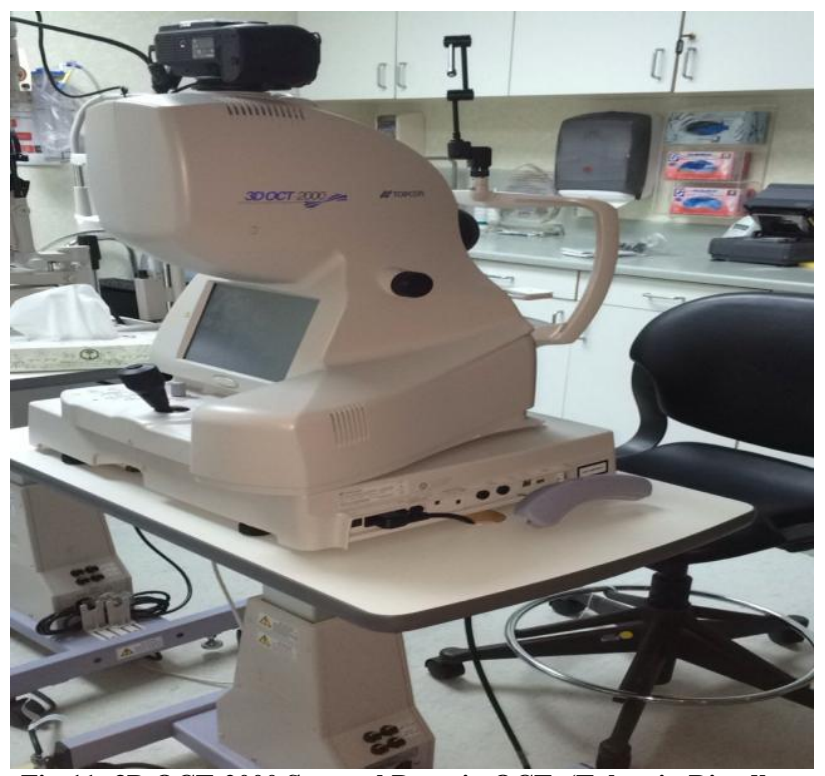

Fig-11: 3D OCT-2000 Spectral Domain OCT. (Taken in Riyadh, King Faisal Specialist Hospital, ophthalmology department, photos room, 8 April 2015)

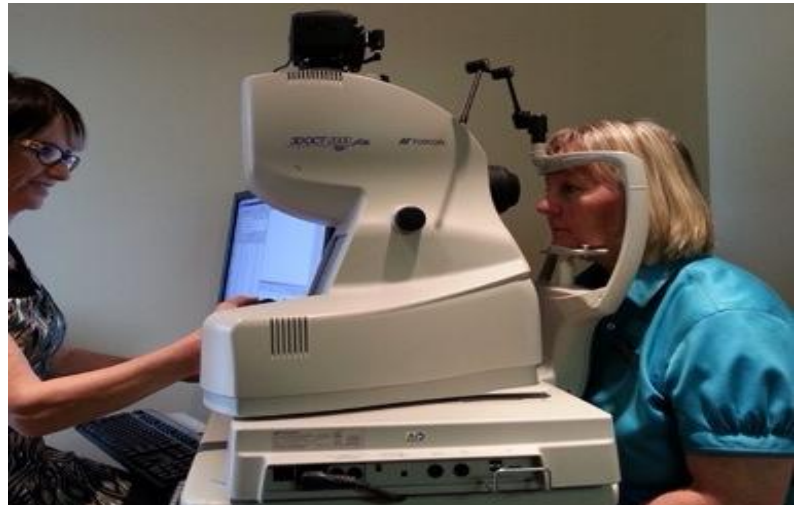

Fig-12: Examination using 3D OCT-2000 Spectral Domain. (Accessed on 12 $2^{\text {th }}$ April 2015).

http://www.airdrieeyecare.com/img/oct-2.jpg

\section{Instruction for use}

- Inform the patient about the test and why it has being done.

- Explain that it is an entirely non-invasive method and would need his / her utmost cooperation for a few minutes only.

- Seat the patient in front of OCT machine.

- Pull the scan head all the way to the back position before asking the patient to place his /her chin rest.

- Adjust the table height and chin rest height to be comfortable for the patient. Also, make sure the patient's canthus approximately even with the marks on the forehead rest supports (Fig.12).

- Insert all the data of the patient in the system of the instrument to create a new session for the patient.

- $\quad$ Select the desired scan (3D Disc Scan in this study) and align the instrument so that fundus image and scan beam will display on the screen.

- Instruct the patient to look into the main lens and to focus on the green fixation light inside the machine. The green light will guide the patient to fixate to the nasal side so the optic disc image will be centered in the OCT scan. The patient will also see the background red lighting and the actual scan pattern being taken as a slightly brighter red light.

- Glide the joystick toward the patient's pupil and move through the pupil until the image of the retina fills the screen.

- Press on the (scan) button.

- When the scan has been captured, the user is ready to proceed to the Analysis Mode to print out the results (Fig.13 and Fig, 14) [47-50]. 


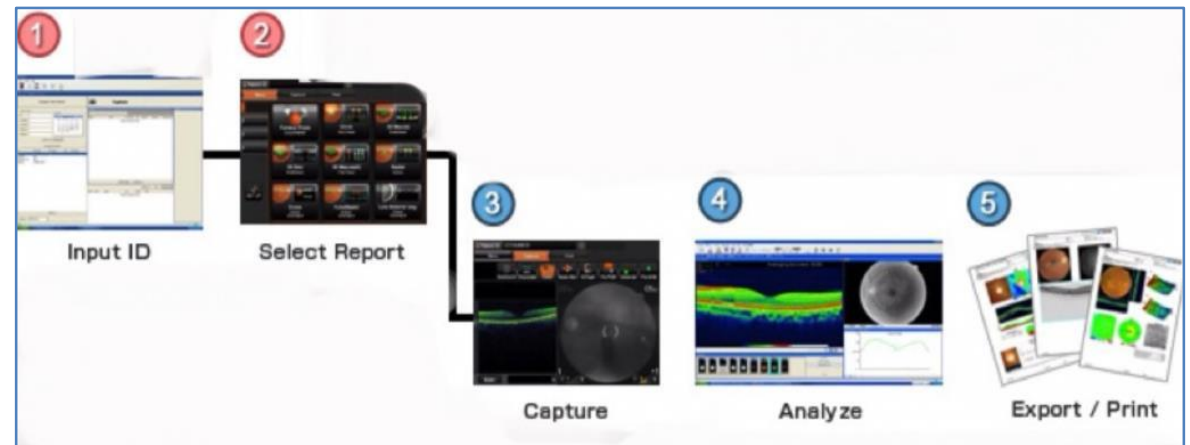

Fig-13: Imaging process using 3D OCT-2000 Spectral Domain OCT. (Accessed and edited on $12^{\text {th }}$ April 2015). http://www.topcon.co.jp/en/eyecare/product/images/diag/oct/oct2000/oct2000_img_06.jpg

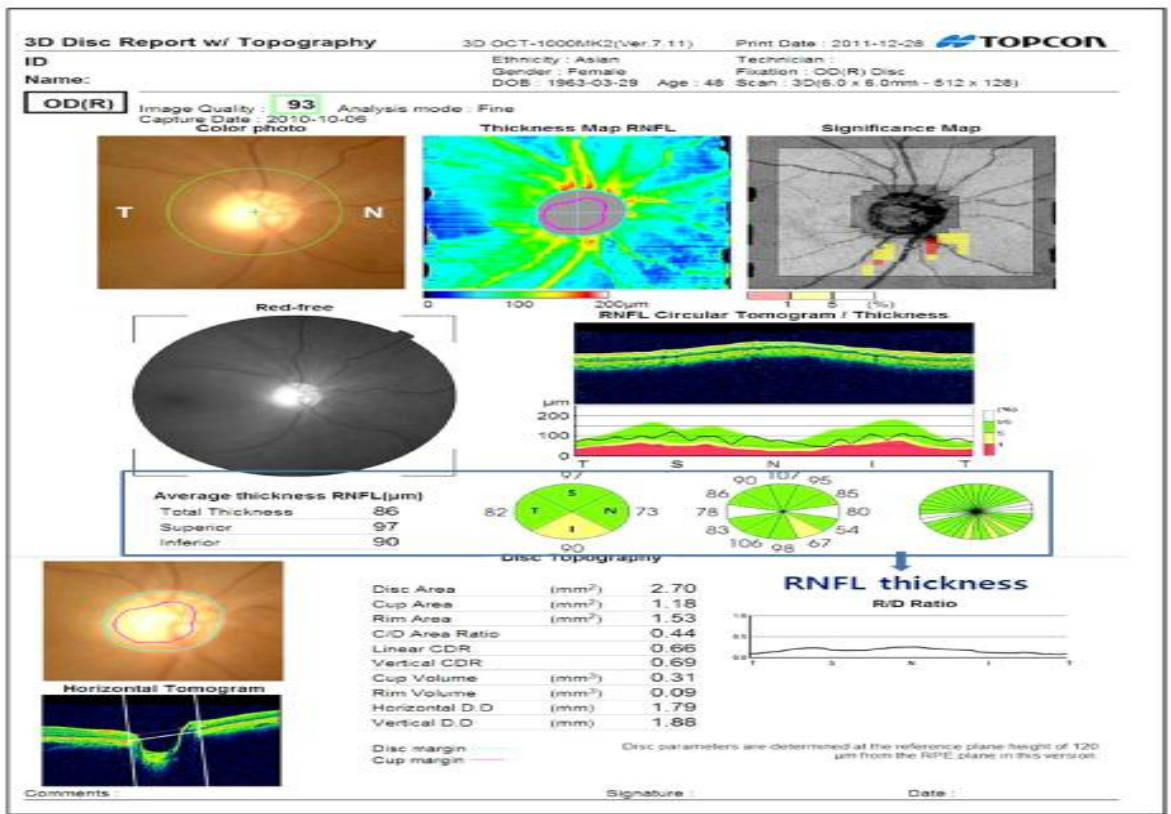

Fig-14: 3D Disc Report using 3D OCT-2000 Spectral Domain OCT. (Accessed on 12 ${ }^{\text {th }}$ April 2015) $^{-12}$ http://synapse.koreamed.org/ArticleImage/0035JKOS/jkos-53-103-g001-l.jpg

\section{Normal values for RNFLT in OCT}

In a study done in Greece to determine peripapillary (RNFL) measured with spectral domain optical coherence tomography (SD-OCT) in normal and glaucomatous eyes in a large sample of exclusively white population, they found that the RNFLT in normal study population followed a bell curve distribution and average RNFL thickness value was $114.8 \pm 13.3 \mu \mathrm{m}$ (Fig.15)[53].

\begin{tabular}{|c|c|c|c|c|}
\hline \multicolumn{5}{|c|}{ Peripapillary retinal nerve fibre layer thickness in normal and glaucomatous eyes } \\
\hline & \multicolumn{4}{|c|}{$\begin{array}{l}\text { Table } 1 \text { RNFL thickness (in } \mu \mathrm{m}+\mathrm{SD}) \text { for normal }(n=278) \text { and glaucomatous }(n=67) \text { optic discs }(P<0.05 \text { was } \\
\text { considered statistically significant) }\end{array}$} \\
\hline & Group A (normal) & Group B (glaucoma) & $P$ & $\begin{array}{l}\text { 95\% Confidence Interval of the Difference } \\
\text { (equal variances not assumed) }\end{array}$ \\
\hline Average & $114.8+13.3$ & $92.1 \pm 18.5$ & $<0.001$ & 17.9 to 27.4 \\
\hline $\operatorname{Max}$ & $184.9+21.5$ & $145.1 \pm 31.2$ & $<0.001$ & 31.8 to 47.8 \\
\hline Min & $53.1 \pm 9.7$ & 49.6 $6 \pm 20.4$ & 0.17 & -1.6 to 8.6 \\
\hline Superior & $136.7 \pm 18$ & $105+25.1$ & 40.001 & 25.3 to 38.2 \\
\hline Nasal & $107.2+17.8$ & $92.3+19.2$ & 80.001 & 9.8 to 20 \\
\hline Inferior & $134.5 \pm 18.1$ & $102.9+24.8$ & $<0.001$ & 25.2 to 38 \\
\hline Temp̨oral & $79.5 \pm 15.3$ & $68.8 \pm 16.5$ & $<0.001$ & 6.3 to 15.1 \\
\hline
\end{tabular}

Fig-15: RNFLT in normal and glaucomatous eyes. (Accessed on $13^{\text {th }}$ April 2015). http://www.ijo.cn/en_publish/2013/5/20130522.pdf 


\section{SATISTICAL ANALYSIS}

All statistical analysis was performed using the Statistical Package for the Social Sciences (SPSS), version 21.0, for MacBook Pro. Data were expressed as mean \pm standard deviation. The normality of the distribution for all variables were tested by the Q-Q plot, histogram and by the Kolmogorov-Smirnov test and it was not normally distributed in $\mathrm{AD}$ and controls group.

All the AD and controls group data were nonparametric independent variables (unpaired), and all the variables were analyzed and compared using MannWhitney U test. All $P$-values were two-tailed and a Pvalue $\leq 0.05$ was considered to indicate statistical significance.

\section{RESULTS}

\section{Demographic data}

This study included 11 patients with $\mathrm{AD}$ (mean age: $67.36 \pm 8.1$ years; age range: $50-78$ years), AD where 7 males and 4 females $(63.3 \%$ males and 36.4 females) (Fig.16). And it was included 11 healthy controls (mean age: $62 \pm 9$ years; age range: 50-79 years), the controls subjects where 5 males and 6 females (45\% males and 55\% females) (Fig.17).

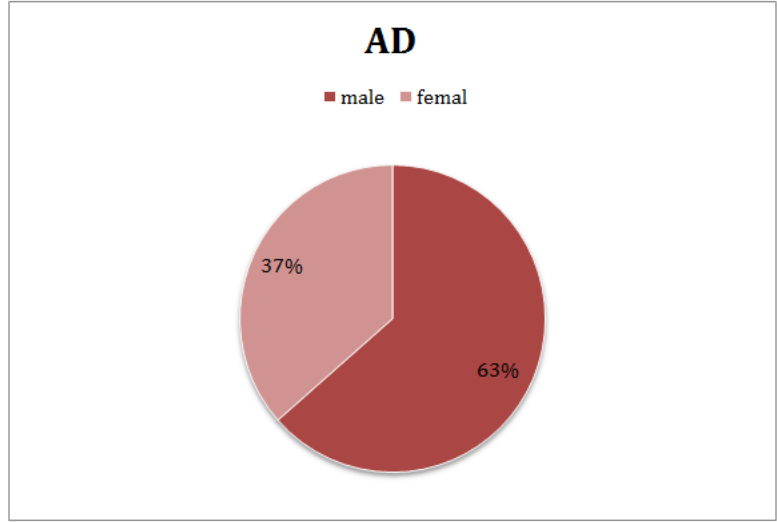

Fig-16: AD group gender ratio

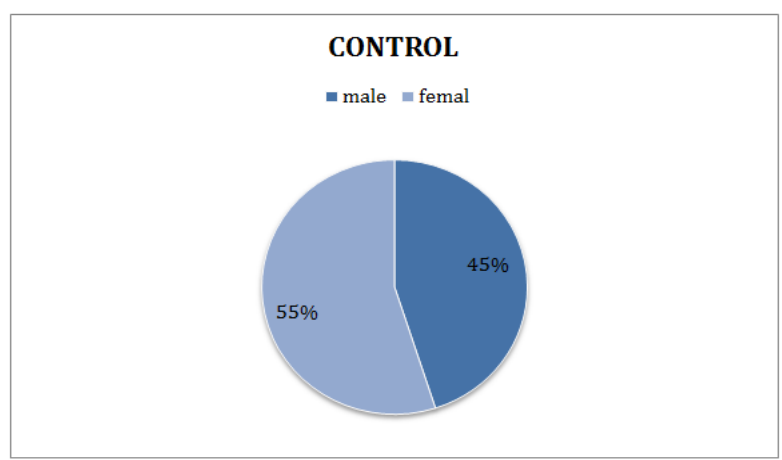

Fig-17: Control group gender ratio

\section{The Retinal Nerve Fiber Layer Thickness Results}

Table-1: The Mean retinal nerve fiber layer thickness $(\mu \mathrm{m})$ in patients with $\mathrm{AD}$ and healthy controls $(\mathrm{mean} \pm \mathrm{SD})$

\begin{tabular}{|c|c|c|c|}
\hline & \multicolumn{2}{|c|}{ Mean RNFL Thickness $(\boldsymbol{\mu m})$} & \\
\hline Quadrant Location & $\mathrm{AD}$ & Controls & P Value \\
\hline Total Thickness* & $84.21 \pm 12.68$ & $98.27 \pm 16.25$ & $0.006^{* *}$ \\
\hline Nasal Thickness* & $67.63 \pm 14.37$ & $88.54 \pm 34.35$ & $0.007^{* *}$ \\
\hline Temporal Thickness & $66 \pm 12.84$ & $71.22 \pm 8.86$ & 0.229 \\
\hline Superior Thickness & $100.57 \pm 17.94$ & $114.86 \pm 21.47$ & 0.11 \\
\hline Inferior Thickness* & $102.21 \pm 22.04$ & $117.77 \pm 21.58$ & $0.010^{* *}$ \\
\hline
\end{tabular}

Patients with AD showed a significant reduction in the total RNFL Thickness Compared to the controls group $(84.21 \pm 12.68 \mu \mathrm{m}$ versus $98.27 \pm 16.25$ $\mu \mathrm{m} ; P=0.006$ ) (Fig.18). Furthermore, the nasal and inferior RNFL thickness were significantly lower in patients with $\mathrm{AD}$ compared to the controls (67.63 \pm $14.37 \mu \mathrm{m}$ versus $88.54 \pm 34.35 \mu \mathrm{m}$ in the nasal quadrant, $102.21 \pm 22.04 \mu \mathrm{m}$ versus $117.77 \pm 21.58$ $\mu \mathrm{m}$ in the inferior quadrant, respectively) with a significant $P=0.007$ and $P=0.010$ in the nasal and the inferior quadrant, respectively as shown in (TABLE 1) (Fig.19, Fig.20 \&Fig.21).

Hence, the mean of the temporal quadrant reveled a reduction in the RNFL thickness AD patients but not statistically significant compared to the matched controls group $(66 \pm 12.84 \mu \mathrm{m}$ versus $71.22 \pm 8.86 \mu \mathrm{m}$; $P=0.229$ ). Also, there was no significant difference between AD Superior RNFL Thickness and the controls $(100.57 \pm 17.94 \mu \mathrm{m}$ versus $114.86 \pm 21.47 \mu \mathrm{m} ; P=$ 0.11) (Fig.21).
Among all the AD peripapillary RNFLT, the thinnest quadrant was the temporal quadrant (mean 66 $\pm 12.84 \mu \mathrm{m})$ (Fig. 19).

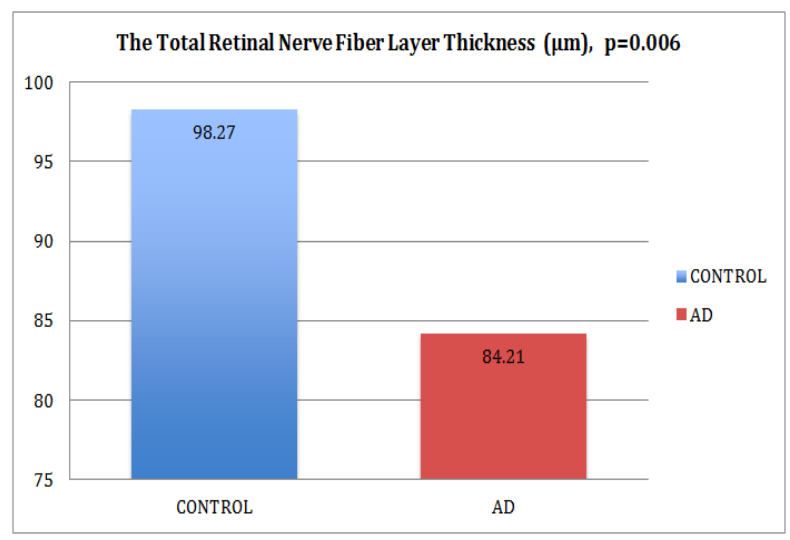

Fig-18: The total retinal nerve fiber layer thickness in AD patients Compared to the total retinal nerve fiber layer thickness in the healthy controls group $(\mu \mathrm{m})$ 


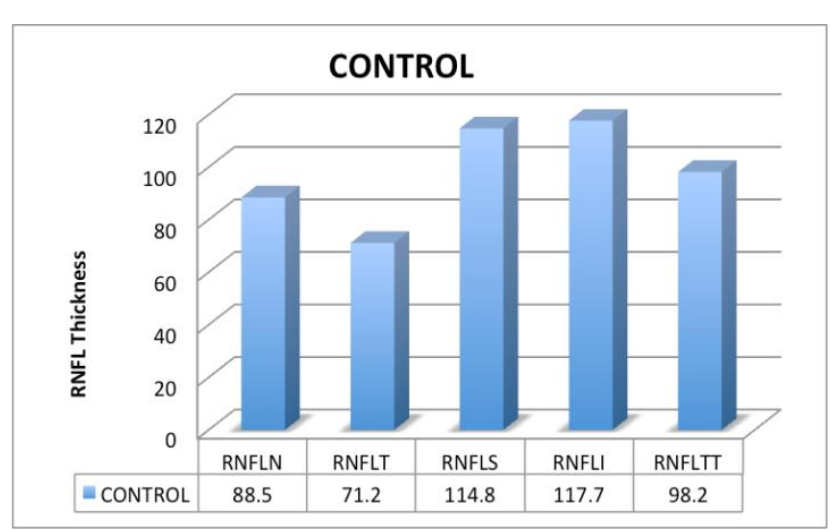

Fig-19: The retinal nerve fiber layer thickness in all the peripapillary quadrants in the healthy controls group $(\mu \mathrm{m})$

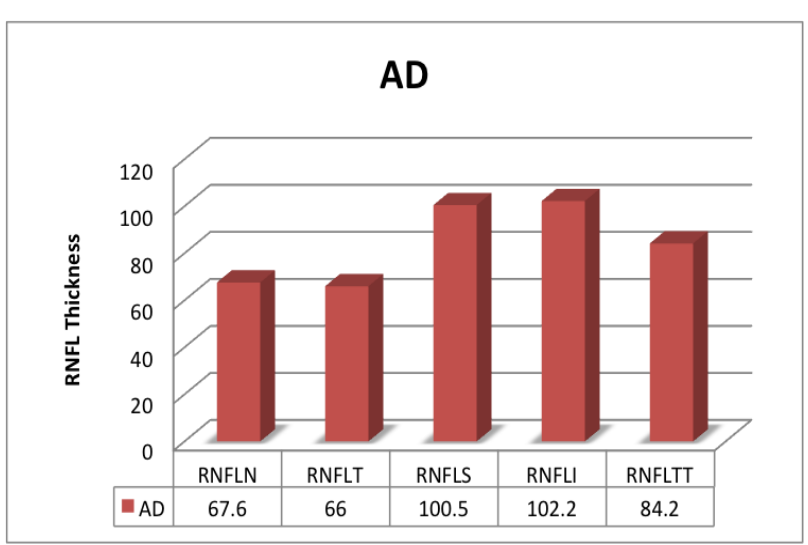

Fig-20: The retinal nerve fiber layer thickness in all the peripapillary quadrants in the AD group $(\mu \mathrm{m})$

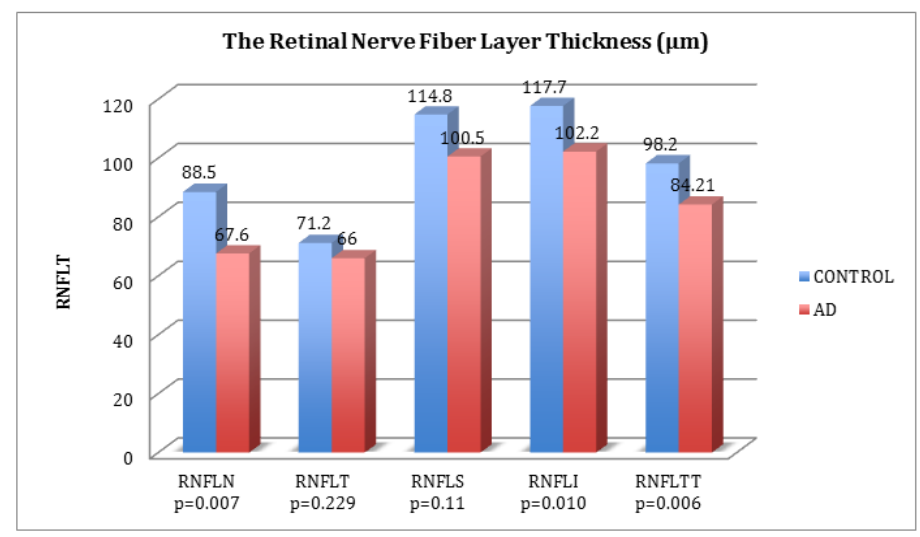

Fig-21: The retinal nerve fiber layer thickness in all the quadrants in the AD group compared to the healthy controls group $(\mu \mathrm{m})$

\section{Optic Disc Parameters results}

Table-2: The optic disc parameters $(\mu \mathrm{m})$ in AD and healthy controls (mean $\pm \mathrm{SD}$ ).

\begin{tabular}{|c|c|c|c|}
\hline & \multicolumn{2}{|c|}{ Mean Size $(\boldsymbol{\mu m})$} & \\
\hline Optic Disc parameters & $\mathrm{AD}$ & Control & P Value \\
\hline C/D Ratio* & $0.35 \pm 0.14$ & $0.2 \pm 0.14$ & $0.003^{* *}$ \\
\hline Cup Volume* & $0.13 \pm 0.08$ & $0.73 \pm 0.08$ & $0.018^{* *}$ \\
\hline Rim Volume & $0.4 \pm 0.22$ & $0.59 \pm 0.32$ & 0.32 \\
\hline
\end{tabular}

The cup volume and rim volume were lower in AD compared to the healthy control group as shown in (TABLE 2) $(0.13 \pm 0.08$ versus $0.73 \pm 0.08$ and $0.4 \pm$ 0.22 versus $0.4 \pm 0.22$; respectively) with a statistically significant $P$ value $=0.018$ for the cup volume between the groups, and no significant difference for the rim volume $(P=0.32)$. Therefore, the $\mathrm{C} / \mathrm{D}$ Ratio was significantly larger in $\mathrm{AD}$ than the controls $(P=0.003)$ (Fig.22).

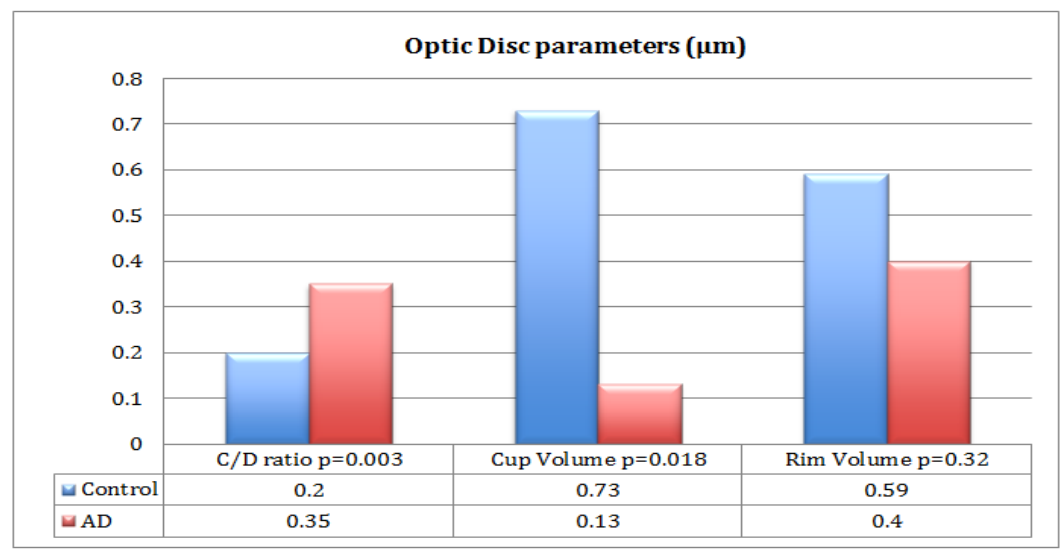

Fig-22: Optic disc parameters $(\mu \mathrm{m})$ in $\mathrm{AD}$ and compared to the healthy controls group (mean $\pm \mathrm{SD})$ 


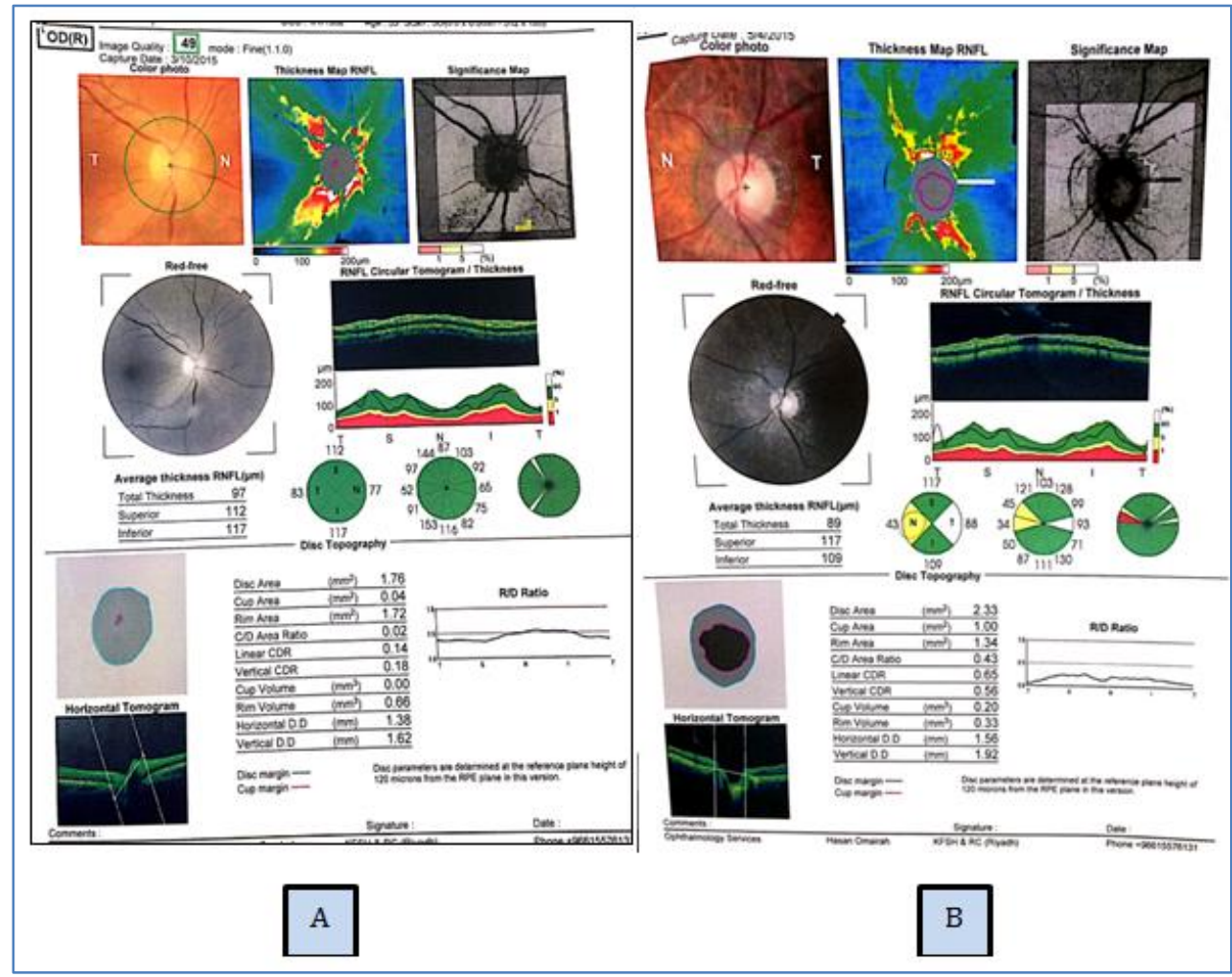

Fig-23: (A) A 3D Disc report using 3D OCT-2000 Spectral Domain, shown a normal retinal nerve fiber layer thickness in the right eye of a healthy subject. (B) A thin retinal nerve fiber layer in the nasal quadrant in the left eye of AD patient as shown in the figure above

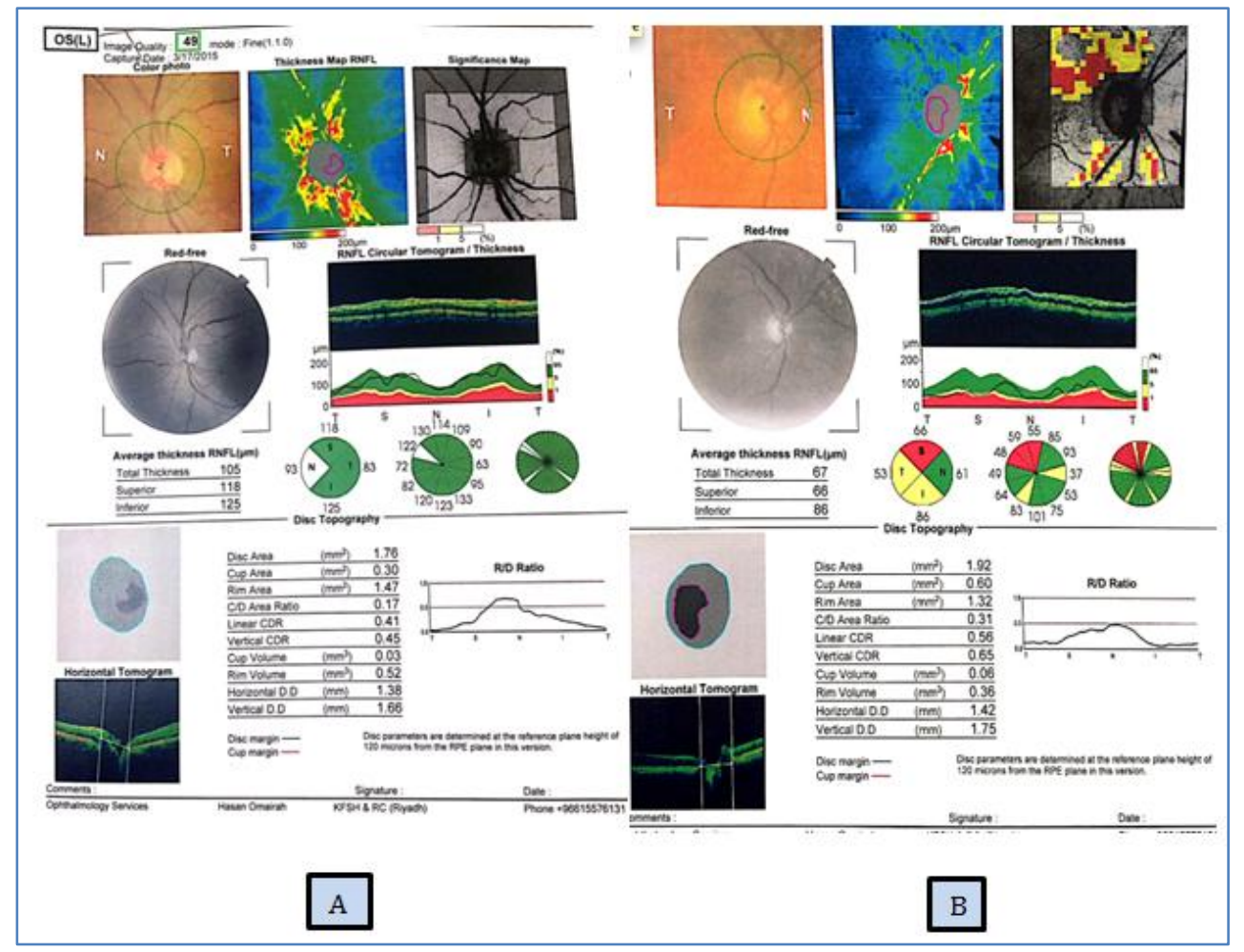

Fig.24: (A) A 3D Disc report using 3D OCT-2000 Spectral Domain, shown a normal retinal nerve fiber layer thickness in the left eye of a healthy subject. (B) A thin retinal nerve fiber layer in the temporal, inferior and superior quadrant in the right eye of AD patient as shown in the figure above 


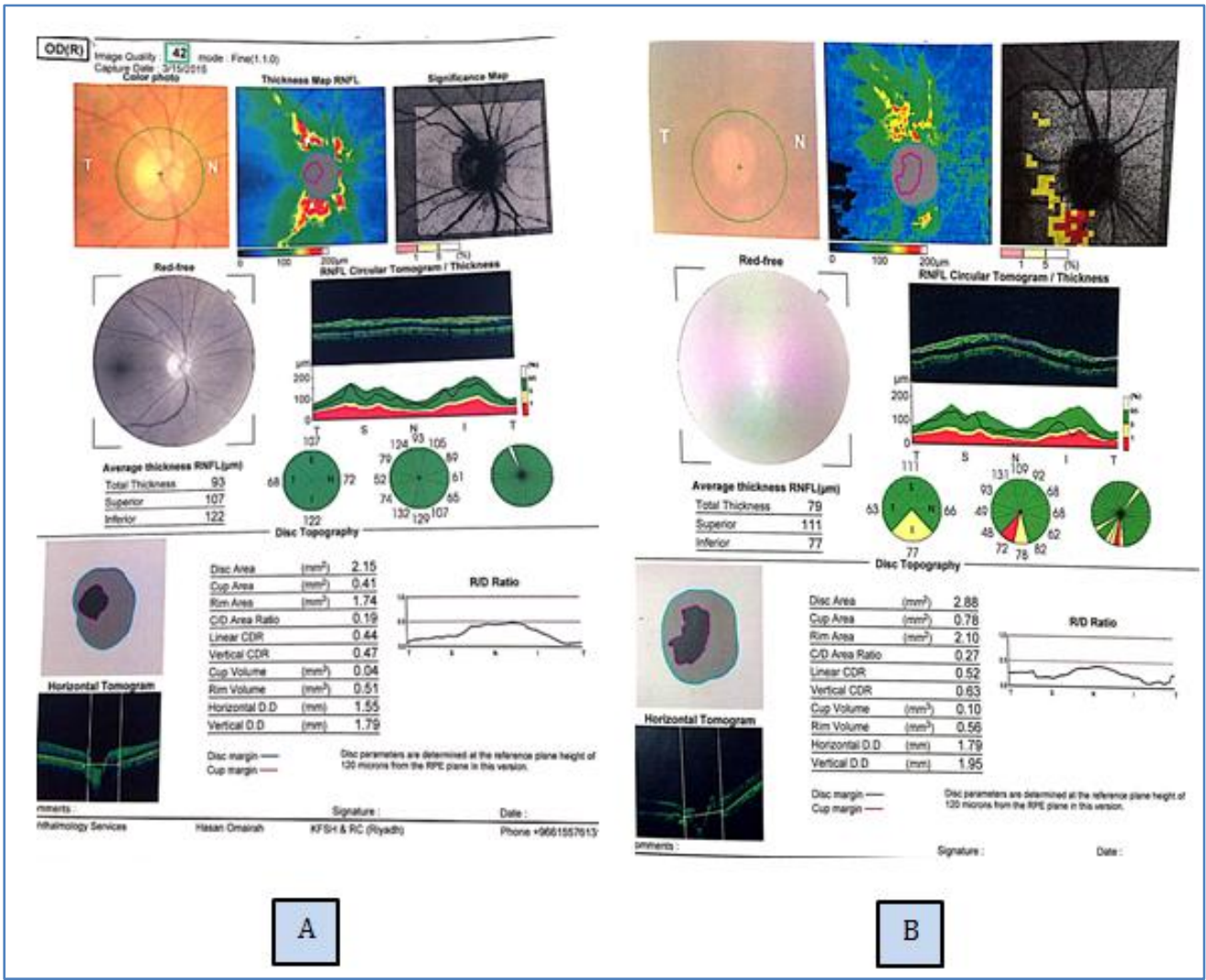

Fig.25: (A) A 3D Disc report using 3D OCT-2000 Spectral Domain, shown a normal retinal nerve fiber layer thickness in the right eye of a healthy subject. (B) A thin retinal nerve fiber layer in the inferior quadrant in the right eye of AD patient as shown in the figure above

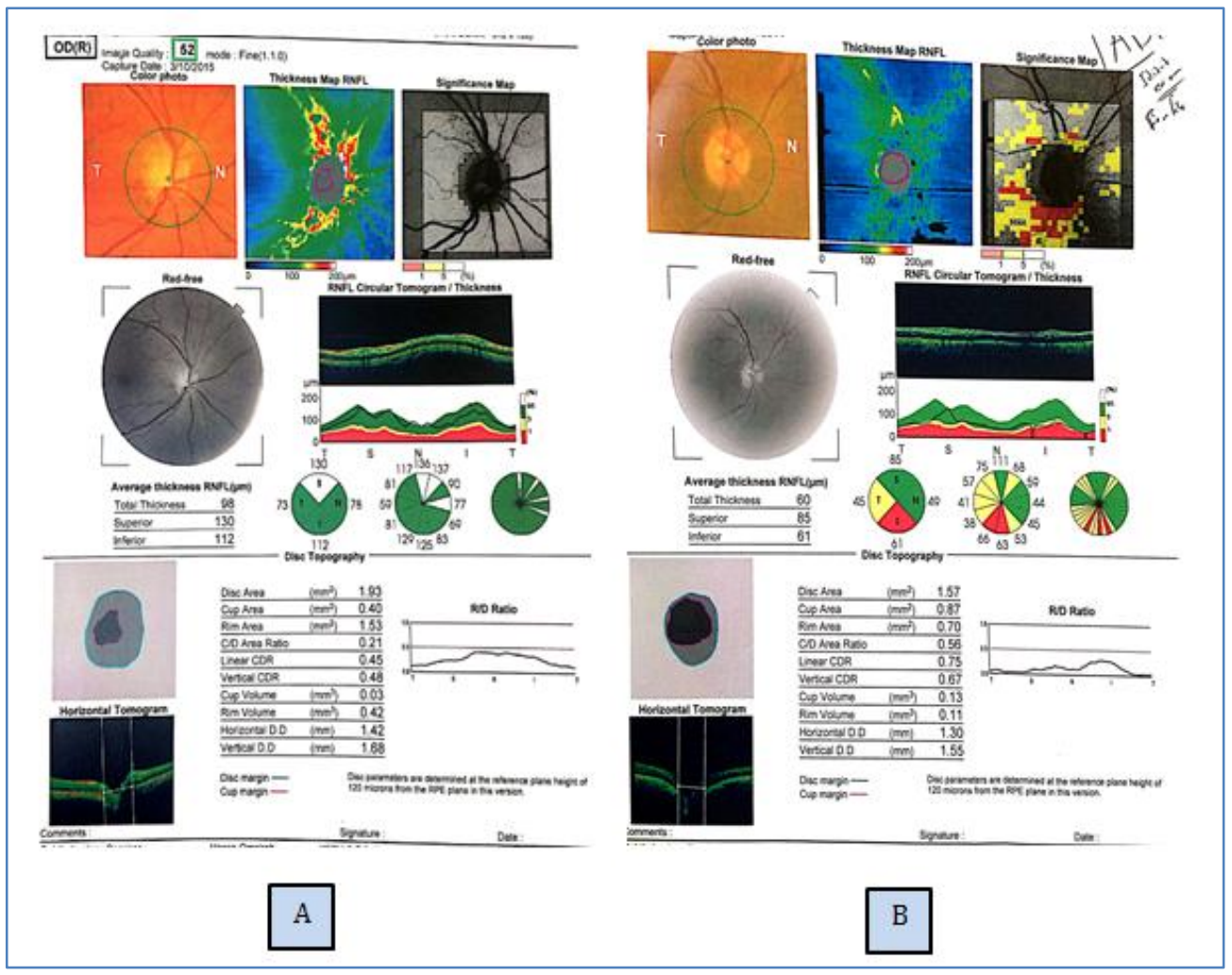

Fig-26: (A) A 3D Disc report using 3D OCT-2000 Spectral Domain, shown a normal retinal nerve fiber layer thickness in the right eye of a healthy subject. (B) A thin retinal nerve fiber layer in the inferior and temporal quadrant in the right eye of AD patient as shown in the figure above 


\section{DISCUSSION}

\begin{tabular}{|c|c|c|c|c|}
\hline $\begin{array}{c}\text { Author } \\
\text { (Reference) }\end{array}$ & $\begin{array}{c}\text { Number of } \\
\text { the patients }\end{array}$ & OCT technique & $\begin{array}{c}\text { Average RNFL } \\
\text { Thickness }\end{array}$ & Defected quadrant \\
\hline Iseri et al. [55] & 14 & TD & $87.46 \pm 23.78$ & Inf.**+ Sup. \\
\hline Berishia et al. [22] & 9 & TD & $98.76 \pm 10.9$ & Sup. \\
\hline $\begin{array}{c}\text { Paguet } \text { et al. } \\
{[56]}\end{array}$ & 12 & TD & $78.8 \pm 4.9$ & $\begin{array}{c}\text { Sup. +Inf.** } \\
\text { Nasal** + Temp. }\end{array}$ \\
\hline Kromer et al. [40] & 22 & SD-OCT & & Nasal**+ Temp. \\
\hline Curcio et al. [58] & 4 & the density of Ganglion Cells & & No RNFL Thinning \\
\hline Current study & 11 & 3D-SD & $84.21 \pm 12.68$ & $\begin{array}{l}\text { Inf.**+ } \\
\text { Nasal** }\end{array}$ \\
\hline
\end{tabular}

Our results demonstrate a total RNFL thickness reduction in the early stages of AD compared with the healthy controls. The reduction was represented as a significant thinning in the RNFL of AD patient as it was verified by numerous previous studies [22, 25, 42, 47, 54]. Alzheimer's patients had a general reduction in all quadrants of the peripapillary RNFL thickness, which was significantly thin in the nasal and inferior quadrants and this is consistent with parallel studies using a different OCT machine (TABLE.3)[40, $42,43,46]$.

Berishia et al., using TD OCT (Time Domain) documented a significant reduction in the RNFL thickness in the superior quadrant and no significant differences in the inferior, temporal, or nasal RNFL thicknesses [22]. Also, Kromer et al., prove that the RNFLT reduced in the nasal superior and the temporal superior sectors only, by using the same machine that Berishia[22] used in his study (TD-OCT) [42]. Moreover, The defect in AD RNFL was represented mainly by the defect and thinning in the superior quadrant as indicated in several researches before with larger sample size and different OCT machine type (Kromer et al. [22 ] patients by SD-OCT)[40] and et al. [40] patients by SD-OCT)[42] which was statistically not significantly reduced in this study (TABLE.3).

Previous studies concluded that no RNFL thinning in the $\mathrm{AD}$ patients by measuring the ganglion cells distribution from an autopsy of AD eye [57-59]. Furthermore, no studies done before proved the contrary of our general results using OCT machine.

The process of degeneration in the Alzheimer's disease primary visual cortex can explain the defect in the visual pathway. The continuous death and loss of the neurons in the brain is caused by the accumulation of amyloid and tau protein as tangles and plaques, respectively, in Alzheimer's patients brain cells $[2,6,7]$. The neurons loss will be followed by a death of the ganglion cells followed by a retinal nerve fiber layer thinning $[6,7]$. Furthermore, the selective degeneration of the retinal nerve fiber layer in the nasal and inferior quadrant remains unknown.

Moreover, our results show a significantly large Cup to Disc ratio in AD patients compared to the healthy controls. Also, the rim volume and the cup volume were smaller in AD than the healthy controls. This finding was significant in the Cup volume and not significant in the Rim volume between the groups. Therefore, these outcomes tell us that the optic nerve is atrophic in $\mathrm{AD}$ compared to controls as it was found by numerous results $[25,42,54,60]$.

\section{CONCLUSION}

Patients with Alzheimer disease exhibit a thinner retinal nerve fiber layer (RNFL) than the healthy control subjects.

\section{RECOMMENDATIONS}

As our study included number of early stages (early and mild) of AD patients and we used latest 3D OCT-2000 Spectral Domain OCT technology, we are able to extend a current evidence. The early diagnosis of $\mathrm{AD}$ with this technique will help in neuroprotective rehabilitations and control in the early stages of the disease. In addition, the future demonstration in the modifications of the degree of RNFL thickness in AD patients over time may prove to be an excellent biomarker to study the degree of the disease.

The limitations of this study are: (i) only patients with a limited range of severity of $\mathrm{AD}$ were included (early and mild) which doesn't help studying the process of the AD. (ii) Only cross-sectional measurements were done without follow-up to investigate the progress of the RNFLT. (iii) The small sample size that will be increased in a complementary study after we get a larger sample size.

On the other hand, the strengths of our study are: (i) patients and controls were age and sex-matched. (ii) 3D OCT-2000 Spectral Domain OCT technology was obtained. (iii) Patients with early stages of $\mathrm{AD}$ (early and mild) were included because we suspect that the differences may not be obvious in the later stages and to exclude the effect of medications that prescribed to slow the progression of the disease such as donepezil. (iv) the clinical diagnosis of $\mathrm{AD}$ was obtained in a specialized behavioral and cognitive clinic by using highly standardized clinical criteria (KFSH, Neuroscience department), and the OCT was done after a full-completed ophthalmic examinations. (v) Our study proves new evidence in The Middle east and in Saudi Arabia. 


\section{REFERENCES}

1. Morris, Jill K. "Is Alzheimer's disease a systemic disease?." Biochimica et Biophysica Acta (BBA)Molecular Basis of Disease 1842.9. 2014: 13401349.

2. Ballios J. "The Alzheimer's Disease: Understanding Alzheimer's Disease and Learn How to Fight it". Createspace Independent Pub Health \& Fitness.2014.

3. Soukup JE. "Alzheimer's Disease: A guide to diagnosis, treatment, and management". Greenwood Publishing Group. United State of America.1996.

4. "Dementia" Fact sheet N³62. March 2015. World health organization. Online at:

http://www.who.int/mediacentre/factsheets/fs362/e $\mathrm{n} /($ Accessed in 18 April 2015)

5. Todd, Stephen. "Survival in dementia and predictors of mortality: a review." International journal of geriatric psychiatry 28.11. 2013: 11091124.

6. “What Is Alzheimer's?". Alzheimer's association. Online at:

http://www.alz.org/alzheimers_disease_what_is_al zheimers.asp\#tangles (Accessed in 18 April 2015)

7. "Dementia: hope through research". National Institute of Neurological Disorders and Stroke. Bethesda, MD: Office of Communications and Public Liaison, National Institute of Neurological Disorders and Stroke, US National Institutes of Health. Published online; (2015, 23 February), at: http://www.ninds.nih.gov/disorders/dementias/dem entia.htm (Accessed in 18 April 2015).

8. McKhann, Guy M. "The diagnosis of dementia due to Alzheimer's disease: Recommendations from the National Institute on Aging-Alzheimer's Association workgroups on diagnostic guidelines for Alzheimer's disease."Alzheimer's \& Dementia. 7.3. 2011: 263-269.

9. NICE. Dementia: Supporting people with dementia and their carers in health and social care. (November 2006). NICE clinical guideline. London, UK: National Institute for Health and Care Excellence,

10. "Stages of Alzheimer's". Alzheimer association. Online at:

http://www.alz.org/alzheimers_disease_stages_of_ alzheimers.asp.(Accessed in 19 April 2015).

11. DeFina PA, Moser RS. "Alzheimer's disease clinical and research update for health care practitioners". Journal of Aging Research, volume 2013 (e-publication, September 4th, 2013.

12. Jun G. "A novel Alzheimer disease locus located near the gene encoding tau protein." Molecular psychiatry; 2015.

13. Philipps, Viviane. "Normalized Mini-Mental State Examination for assessing cognitive change in population-based brain aging studies."Neuroepidemiology. 43.1. 2014: 15-25.
14. Hodkinson HM. "Evaluation of a mental test score for assessment of mental impairment in the elderly." Age and ageing 1.4. 1972: 233-238.

15. O'Bryant, Sid E. "A blood-based screening tool for Alzheimer's disease that spans serum and plasma: findings from TARC and ADNI." PloS one 6.12. 2011: e28092.

16. Stamps, Jennifer J, Linda M. Bartoshuk, and Kenneth M. Heilman. "A brief olfactory test for Alzheimer's disease." Journal of the neurological sciences 333.1. 2013: 19-24.

17. Shi, Zhongyong. "Greater Attenuation of Retinal Nerve Fiber Layer Thickness in Alzheimer's Disease Patients." Journal of Alzheimer's Disease40.2. 2014: 277-283.

18. Rayan, Stephen J. Retina. Los Angeles CA, USA. Elsevier Health Sciences, 2013.

19. Shepherd, Gordon. The Synaptic Organization of the Brain. New York, NY: Oxford University Press. 2004: 217-225.

20. Pardianto, Gede. "Retinal thickness changes after phacoemulsification." Clinical ophthalmology (Auckland, NZ) 7. 2013: 2207.

21. Chang, Lily YL. "Alzheimer's disease in the human eye. Clinical tests that identify ocular and visual information processing deficit as biomarkers."Alzheimer's \& Dementia 10.2. 2014: 251-261.

22. Berisha, Fatmire. "Retinal abnormalities in early Alzheimer's disease."Investigative ophthalmology \& visual science 48.5. 2007: 2285-2289.

23. Ohno-Matsu K. Parallel findings in age-related macular degeneration and Alzheimer's disease. Prog Retin Eye Res. 2011; 30:217-238.

24. Baranello J, Robert. "Amyloid-beta protein clearance and degradation (ABCD) pathways and their role in Alzheimer's disease." Current Alzheimer Research. 12.1 2015: 32-46.

25. Guo LJ, Duggan and MF. Cordeiro. "Alzheimer's disease and retinal neurodegeneration." Current Alzheimer Research 7.1. 2010: 3-14.

26. Elyashiv, Sivan M. "Correlation between visual acuity and cognitive functions." British Journal of Ophthalmology 98.1. 2014: 129-132.

27. Rizzo, Matthew. "Vision and cognition in Alzheimer's disease."Neuropsychologia 38.8. 2000: 1157-1169.

28. Cormack, Francesca K., Martin Tovee, and Clive Ballard. "Contrast sensitivity and visual acuity in patients with Alzheimer's disease." International journal of geriatric psychiatry 15.7. 2000: 614-620.

29. Gilmore, Grover C., and JAMES A. LEVY. "Spatial contrast sensitivity in Alzheimer's disease: a comparison of two methods." Optometry \& Vision Science 68.10. 1991: 790-794.

30. Risacher, Shannon L. "Visual contrast sensitivity in Alzheimer's disease, mild cognitive impairment, and older adults with cognitive complaints."Neurobiology of aging 34.4. 2013: 1133-1144. 
31. Cernin, Paul A, Brenda K. Keller and Julie A. Stoner. "Color vision in Alzheimer's patients: Can we improve object recognition with color cues?."Aging, Neuropsychology, and Cognition 10.4. 2003: 255-267.

32. Postuma, Ronald B. "Olfaction and color vision identify impending neurodegeneration in rapid eye movement sleep behavior disorder." Annals of neurology 69.5. 2011: 811-818.

33. Brewer, Alyssa A and Brian Barton. "Visual cortex in aging and Alzheimer's disease: changes in visual field maps and population receptive fields." Frontiers in psychology 5. 2014.

34. Fletcher, William A., and James A. Sharpe. "Saccadic eye movement dysfunction in Alzheimer's disease." Annals of neurology 20.4; 1986: 464-471.

35. Fletcher, William A and James A. Sharpe. "Smooth pursuit dysfunction in Alzheimer's disease." Neurology 38.2. 1988: 272-272.

36. Morrow, Mark J and James A. Sharpe. "Smooth pursuit initiation in young and elderly subjects." Vision research 33.2; 1993: 203-210.

37. Holroyd, Suzanne, Michael L. Shepherd and J. Hunter Downs III. "Occipital atrophy is associated with visual hallucinations in Alzheimer's disease." 2014.

38. Liu, Dachuan. "Thinner changes of the retinal never fiber layer in patients with mild cognitive impairment and Alzheimer's disease." BMC neurology 1; 2015: 14.

39. Ci Y, Wang YH, Yang L. The investigation of retinal nerve fiber loss in Alzheimer's disease. Zhonghua Yan Ke Za Zhi. 2010; 46:134-139.

40. Kromer, Robert. "Detection of retinal nerve fiber layer defects in Alzheimer's disease using SDOCT." Frontiers in psychiatry. 5; 2014.

41. Ferrari L. "Retinal nerve fiber layer thinning as a mirror of neurodegeneration in Alzheimer's disease." Clinical Neurophysiology. 126.1; 2015: e8.

42. Kirbas, Serkan. "Retinal nerve fiber layer thickness in patients with Alzheimer disease." Journal of Neuro-Ophthalmology. 33.1; 2013: 58-61.

43. Kesler Anat. "Retinal thickness in patients with mild cognitive impairment and Alzheimer's disease." Clinical neurology and neurosurgery 113.7. 2011: 523-526.

44. Simao, Luciano M. "The contribution of optical coherence tomography in neurodegenerative diseases." Current opinion in ophthalmology. 24.6. 2013: 521-527.

45. Frost S, Martins RN, Kanagasingam Y. Ocular biomarker for early detection of Alzheimer's disease. J Alzheimers Dis. 2010; 22:1-16.

46. Pasol J. Neuro-ophthalmic disease and optical coherence tomography: glaucoma look-alikes. Curr Opin Ophthalmol. 2011; 22:124-132.
47. Greenberg BM, Frohman E. Optical coherence tomography as a potential readout in clinical trials. Ther Adv Neurol Disord. 2010; 3:153-160.

48. Bezerra, Hiram G. "Intracoronary optical coherence tomography: a comprehensive review: clinical and research applications." JACC: Cardiovascular Interventions 2.11. 2009: 10351046.

49. "3D OCT-2000 Spectral Domain OCT". topconmedical. (Accessed on 12 April 2015). Online http://www.topconmedical.com/products/3doct200 $0 . \mathrm{h}$

50. Hou Randy. "Recent advances in optical coherence tomography for the diagnoses of lung disorders." 2011: 711-724.

51. Guedes, Viviane. "Optical coherence tomography measurement of macular and nerve fiber layer thickness in normal and glaucomatous human eyes." Ophthalmology 110.1 2003: 177-189.

52. Serbecic, Nermin. "High resolution spectral domain optical coherence tomography (SD-OCT) in multiple sclerosis: the first follow up study over two years." PLoS One 6.5. 2011: e19843.

53. Kampougeris, George. "Peripapillary retinal nerve fibre layer thickness measurement with SD-OCT in normal and glaucomatous eyes: distribution and correlation with age." International journal of ophthalmology 6.5; 2013: 662 .

54. Ikram, Mohammad Kamran. "Retinal pathology as biomarker for cognitive impairment and Alzheimer's disease." Journal of Neurology, Neurosurgery \& Psychiatry; 2012: Jnnp; 2011.

55. Iseri, Pervin K. "Relationship between cognitive impairment and retinal morphological and visual functional abnormalities in Alzheimer disease." Journal of neuro-ophthalmology 26.1; 2006: 18-24.

56. Paquet, Claire. "Abnormal retinal thickness in patients with mild cognitive impairment and Alzheimer's disease." Neuroscience letters 420.2; 2007: 97-99.

57. Kergoat, Hélène. "An evaluation of the retinal nerve fiber layer thickness by scanning laser polarimetry in individuals with dementia of the Alzheimer type." Acta Ophthalmologica Scandinavica. 79.2; 2001: 187-191.

58. Curcio, Christine A and David N. Drucker. "Retinal ganglion cells in Alzheimer's disease and aging." Annals of neurology. 33.3. 1993: 248-257.

59. Davies DC. "Myelinated axon number in the optic nerve is unaffected by Alzheimer's disease." British journal of ophthalmology. 79.6. 1995: 596-600.

60. Tsai, Clark S. "Optic nerve head and nerve fiber layer in Alzheimer's disease." Archives of ophthalmology, 109.2. 1991: 199-204. 